\title{
BMG Global Heatth Enhancing science preparedness for health emergencies in Africa through research capacity building
}

\author{
Sam Kinyanjui (D) , ${ }^{1,2}$ Sharon Fonn (D) , ${ }^{3}$ Catherine Kyobutungi, ${ }^{4}$ \\ Marta Vicente-Crespo, ${ }^{4}$ Bassirou Bonfoh, ${ }^{5}$ Thumbi Ndung'u, ${ }^{6}$ \\ Nelson Kaulukusi Sewankambo, ${ }^{7}$ Abdoulaye A Djimde, ${ }^{8}$ Oumar Gaye, ${ }^{9}$ \\ Tobias Chirwa, ${ }^{10}$ Eustasius Musenge, ${ }^{11}$ Alison Elliott, ${ }^{12,13}$ Damalie Nakanjako, ${ }^{7}$ \\ Dixon Chibanda, ${ }^{14}$ Gordon Awandare ${ }^{15}$
}

To cite: Kinyanjui S, Fonn S, Kyobutungi $\mathrm{C}$, et al. Enhancing science preparedness for health emergencies in Africa through research capacity building. BMJ Global Health 2020;5:e003072. doi:10.1136/ bmjgh-2020-003072

Received 3 June 2020 Revised 7 June 2020 Accepted 8 June 2020
Check for updates

(C) Author(s) (or their employer(s)) 2020. Re-use permitted under CC BY-NC. No commercial re-use. See rights and permissions. Published by BMJ.

For numbered affiliations see end of article.

Correspondence to Dr Sam Kinyanjui; skmuchina@kemri-wellcome. org
With more than 9.3 million cases and 480000 deaths recorded to date, ${ }^{1}$ COVID-19 pandemic has put global emergency preparedness and the capacity of national health systems to predict and respond to major emergencies under a sharp scrutiny. The response to the pandemic is focused on testing, case management and control measures such as personal hygiene, quarantine and social distancing. However, in most African countries, as elsewhere, these measures are not backed by reliable context-specific data. Instead, they are largely dependent on epidemic curves from China and Europe which appear to differ from those in sub-Saharan Africa. Given the massive economic and social disruptions occasioned by the control measures, governments and other stakeholders are desperate for accurate real-time data on the pandemic's progress and to inform intervention strategies. Furthermore, scarcity of medical and laboratory resources due to increased demand globally coupled with international travel restrictions has forced countries to look inwards for local innovations and adaptations in COVID-19 testing options and interventions, as well as personal protective equipment (PPE)

Consequently, attention has turned to the contribution of local researchers in the pandemic response and by extension, countries' science preparedness. With respect to health emergencies, science preparedness can be defined as 'a collaborative effort to establish and sustain a scientific research framework that can inform and enable emergency planners, responders and the whole community to better prepare for, respond to, and recover from major public health emergencies and disasters'. ${ }^{2}$ As such, science preparedness is an integral part of emergency responsiveness despite receiving less attention than health service preparedness. Although researchers, research support personnel, research infrastructure and mobilisable resources form the core of science preparedness, mounting a robust science-backed emergency recovery response entails complex interplay between multiple elements and actors. As illustrated in figure 1 , mechanisms to expedite ethical approval of emergency research should be in place to fast track the generation and sharing of the data and evidence required to inform response planning and implementation. On the other hand, research should be coordinated to promote synergies and resource optimisation. Furthermore, rapid dissemination and translation of emergency research outputs calls for efficient channels of engagement between researchers, state and nonstate agencies, and the public.

Together, these elements define a responsive and resilient research system that operates and provides reliable data even under crisis. Such a system cannot be hurriedly cobbled together at the dawn of an emergency. Science preparedness should be embedded within a wider scientific capacity building agenda. Given the low research capacity in many Sub-Saharan African countries, there has been some anxiety and fear regarding the ability of the continent's research community to provide scientific backup to COVID-19 response. However, the last decade or so has seen a significant increase in funding for research capacity in Africa. The inevitable question is whether this investment has impacted on the continent's science preparedness. We address this question by reflecting on how research expertise, 


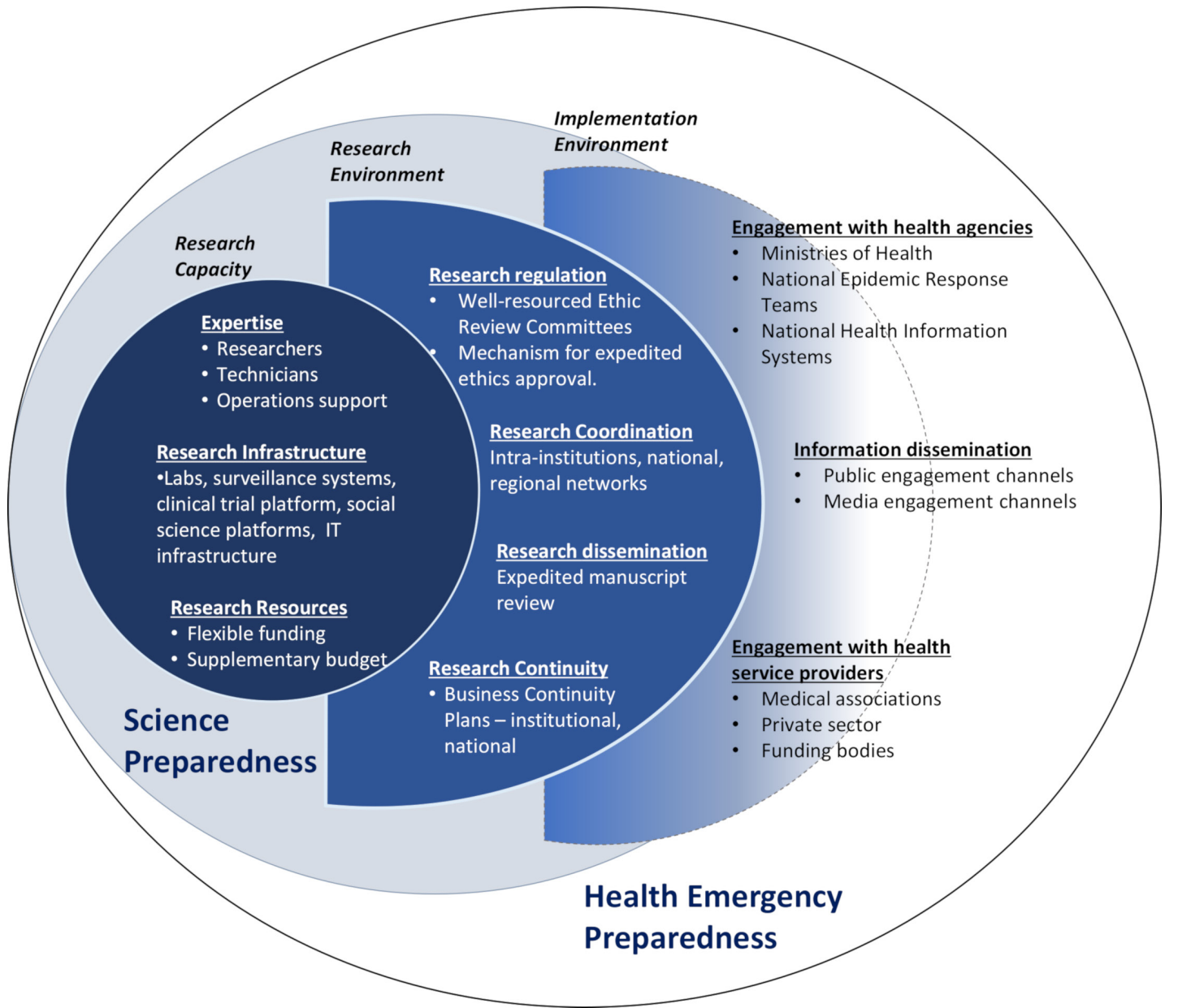

Figure 1 Science preparedness as a component of health emergency preparedness.

infrastructure and resources established under one of the largest networks for research capacity building in Africa has been mobilised for pandemic response and what factors have influenced the level and nature of the network's involvement.

The African Research Coalition for Health (ARCH) is an umbrella network of 11 African-led consortia covering 54 African research institutions and universities across 17 Sub-Saharan countries whose aim is to build high-quality research capacity in the continent. Some consortia have a narrow focus Sub-SaharanAfrican Network for TB/HIV Research Excellence (SANTHE) focuses on HIV and tuberculosis, DevelopingExcellence in Leadership and Genetic Training for Malaria Elimination inSub-Saharan Africa (DELGEME) —-malaria, MalariaResearch Capacity Development in West and Central Africa (MARCAD) malaria and -African Mental Health Research Initiative (AMARI) - mental health. Others such as the Initiativeto Develop African Research Leaders (IDeAL), Makerere University - Uganda Virus Research Institute (UVRI) Centre of Excellence for Infection \& Immunity Research and Training (MUII-plus), WestAfrican Centre for Cell Biology of Infectious Pathogens (WACCBIP) and TrainingHealth Researchers into Vocational Excellence (THRiVE) have a multidisease focus. AfricanScience Partnership for Intervention Research Excellence
(Afrique-one ASPIRE) focuses on One Health implementation research while Sub-SaharanAfrican Consortium for Advanced Biostatistical Training (SSACAB)'s key interest is in enhancing biostatistical leadership and capacity. Consortiumfor Advanced Research Training in Africa (CARTA+) combines an agenda to strengthen $\mathrm{PhD}$ training with multidisciplinary research capacity strengthening at local universities. A large portion of the funds for setting up the consortia came from the Wellcome Trust African Institutions Initiative grant in 2009 and subsequently in 2015 from the Wellcome Trust, The Department for International Development (UKAID) and New Partnership for Africa's Development Planning and Coordinating Agency through the African Academy of Sciences - Developing Excellence in Leadership, Training and Science Africa scheme (DELTAS). ${ }^{3}$ In addition, the consortia have also raised significant amounts of further funding from other sources across the globe. By the end of 2021, ARCH will have supported over 1000 high-quality $\mathrm{PhD}$ and postdoctoral training covering most of the spheres of health research and similar numbers of Master's training, and graduate research internships with the ultimate aim of creating a critical mass of African research leaders.

A quick survey across the members of ARCH 4 months into the pandemic revealed extensive mobilisation of 
Table 1 Examples of capacities mobilised by members of African Research Coalition for Health (ARCH) for COVID-19 response

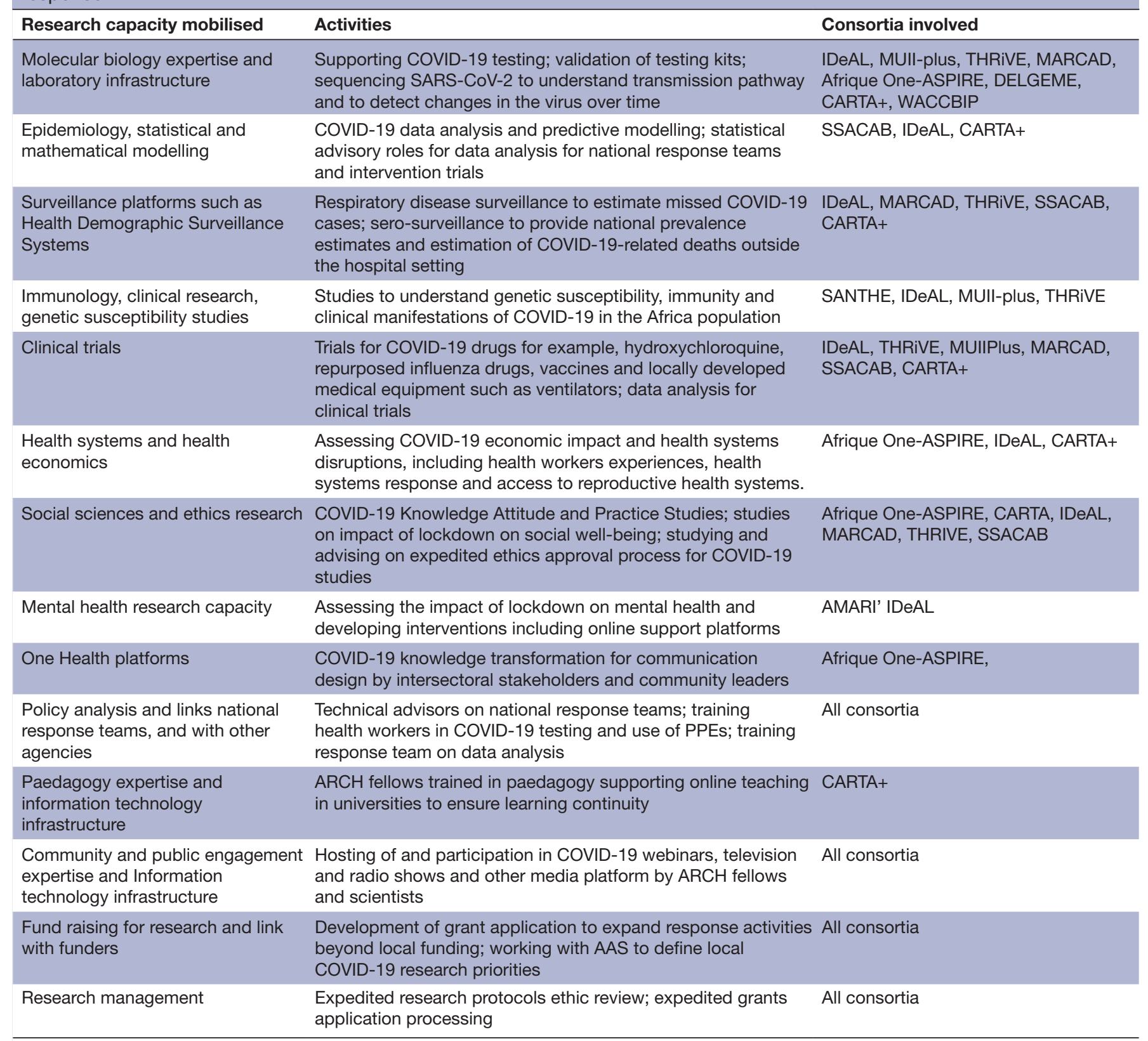

AAS, African Academy of Sciences; SARS-CoV-2, severe acute respiratory syndrome coronavirus 2.

their expertise and resources towards the COVID-19 response (table 1). The most urgent demand globally is for testing expertise and platforms. Because of their established biosciences capacity, many ARCH partner institutions were among the first COVID-19 testing and diagnostics training nodes in their respective countries. Beyond testing, the institutions have also deployed their surveillance systems, and expertise in epidemiology, modelling and pathogen sequencing, a significant proportion of which was developed under the ARCH framework, to gather the population-level data needed to improve incidence estimates and transmission models reliability. ${ }^{4}$ In parallel, many ARCH-trained researchers are currently launching immunology and pathogenesis studies to inform COVID-19 drug and vaccine development. Although clinical trials capacity in Sub-Saharan Africa is limited, ARCH has supported the development of some of the best capacity for trials in the region and at least four consortia are preparing to support clinical trials for COVID-19 vaccines and drugs.

The response to COVID-19 calls for a multisectoral, multiagency One-Health approach structured around core governmental teams supported by technical advisors. Building on the links that ARCH consortia have established with their local state health agencies and in recognition of the expertise the consortia harbour, over 30 ARCH-affiliated scientists and training fellows have been formally appointed to their respective national 
COVID-19 response teams to advise on a range of activities. Those with statistical background are providing support for data analysis and modelling. Social scientists, health systems, policy and mental health researchers are helping assess the impact of COVID-19 control policies on the economy, other health services, social and mental well-being ${ }^{5}$ and advising on mitigation strategies including control models using One-Health platforms. Further, several ARCH ethics researchers have been involved in developing guidelines for expedited ethics review and approval for COVID-19 studies.

We believe that the extensive involvement of ARCH researchers and training fellows in COVID-19 response reflects the quality of capacity built through ARCH. The unique feature of ARCH's model is the underpinning theory of change which encompasses four domains of scientific leadership: research training; scientific excellence; scientific citizenship and research management. ARCH trainees acquire a high level of technical competence through a triad of high-quality supervision, mentorship and well-designed research projects. This competence is supplemented with leadership skills through scientific citizenship training including teaching, community and public engagement. ARCH also lays a strong emphasis on retention and nurturing of researchers beyond training. Without a conducive environment, many risks a stunted research career and may migrate out of Africa or research. ARCH, therefore, promotes an enabling environment within their partner institutions through the development of research infrastructure and research management systems.

This broad view of research capacity building has generated a cohort of prolific African researchers many of whom are not only leading their own research programmes but are also fostering strong collaborations between the consortia and local ministries of health and other key health stakeholders to drive translation and implementation of research output. Furthermore, this approach inherently integrates preparedness for novel health challenges. Thus, when the pandemic reached Africa, the consortia were able to rapidly deploy and redirect their expertise, research resources, infrastructures and links with health agencies to support response activities. Crucial to the response was the ability of the member institutions to rapidly adapt their research regulatory systems to expedite ethics review processes for COVID-19 studies and applications for grants to support the studies.

The research capacity established by ARCH is a strong demonstration of the value of long-term and substantial investment in research capacity building. However, the number of African researchers still falls far short of critical mass and many countries are still excluded from efforts such as ARCH due to insufficiency of funding. In the light of the current pandemic, we the directors of ARCH, urge African governments, and other research funders to seriously reflect on the commitments they have repeatedly made to build science capacity. Second, despite the expertise, infrastructure and resources that
$\mathrm{ARCH}$ and other African institutions have mobilised for COVID-19 responses, the pandemic has revealed critical gaps in Africa's science preparedness. Many institutions are hamstrung by an inability to procure key reagents, goods and services for laboratory and field-based research for COVID-19 and other diseases due to lockdown and travel restrictions. Although system-wide and impacting all sectors, these issues highlight the urgent need to strengthen institutional and national business continuity plans for research during major crises. We would, therefore, like to end this editorial with a call for more investments towards enhancing the resilience of national and global research procurement and supply systems in parallel with building capacity for research that is locally appropriate and responsive to context-specific priorities and needs. ${ }^{6}$

\section{Author affiliations}

${ }^{1}$ Training, Centre for Geographic Medicine Research Coast, Kilifi, Kenya

${ }^{2}$ Nuffield Department of Clinical Medicine, University of Oxford, UK

${ }^{3}$ Public Health, University of the Witwatersrand, Johannesburg-Braamfontein, South Africa

${ }^{4}$ African Population and Health Research Center, Nairobi, Kenya

${ }^{5}$ Centre Suisse de Recherches Scientifiques en Cote d'Ivoire, Abidjan, Lagunes, Côte d'Ivoire

${ }^{6}$ Africa Health Research Institute, Durban, Kwa-Zulu Natal, South Africa

${ }^{7}$ Department of Medicine, School of Medicine, Makerere University College of Health Sciences, Kampala, Uganda

${ }^{8}$ Pharmacy, Malaria Research and Training Center, Bamako, Mali

${ }^{9}$ Cheikh Anta Diop University, Dakar, Senegal

${ }^{10}$ School of Public Health, University of the Witwatersrand School of Public Health, Johannesburg, Gauteng, South Africa

${ }^{11}$ School of Public Health, University of the Witwatersrand Faculty of Science, Johannesburg, South Africa

${ }^{12}$ Uganda Virus Research Institute, Entebbe, Wakiso, Uganda

${ }^{13}$ London School of Hygiene \& Tropical Medicine, London, UK

${ }^{14}$ College of Health Sciences, University of Zimbabwe, Harare, Zimbabwe

${ }^{15}$ West African Center for Cell Biology of Infectious Pathogens, University of Ghana College of Basic and Applied Sciences, Accra, Ghana

Twitter Bassirou Bonfoh @babonfoh

Acknowledgements This manuscript was published with the permission of the KEMRI Director General.

Contributors SK wrote the first draft of the editorial. All authors reviewed the draft and agreed on the final version.

Funding ARCH are all consortia funded by the DELTAS Africa Initiative The DELTAS Africa Initiative is an independent funding scheme of the African Academy of Sciences's Alliance for Accelerating Excellence in Science in Africa (AESA) and supported by the New Partnership for Africa's Development Planning and Coordinating Agency (NEPAD Agency) with funding from the Wellcome Trust (UK) and the UK government. In addition, CARTA is also funded by the Carnegie Corporation of New York (Grant no B8606.R02), Sida (Grant no: 54100029). All the consortia have additional funding from other diverse funders.

Competing interests None declared.

Patient consent for publication Not required.

Provenance and peer review Not commissioned; internally peer reviewed.

Data availability statement № additional data are available.

Open access This is an open access article distributed in accordance with the Creative Commons Attribution Non Commercial (CC BY-NC 4.0) license, which permits others to distribute, remix, adapt, build upon this work noncommercially, and license their derivative works on different terms, provided the original work is properly cited, appropriate credit is given, any changes made indicated, and the use is non-commercial. See: http://creativecommons.org/ licenses/by-nc/4.0/. 
ORCID iDs

Sam Kinyanjui http://orcid.org/0000-0002-3910-0450

Sharon Fonn http://orcid.org/0000-0001-6115-8707

\section{REFERENCES}

1 COVID-19 Coronavirus pandemicORONAVIRUS PANDEMIC Available: https://www.worldometers.info/coronavirus/ [Accessed 6 Jun 2020].

2 What is science preparedness? Available: https://www.phe.gov/ Preparedness/planning/science/Pages/overview.aspx
3 Developing excellence leadership training and science in Africa (DELTAS). Available: https://www.aasciences.africa/aesa/ programmes/developing-excellence-leadership-training-and-scienceafrica-deltas-africa

4 WACCBIP scientists sequence genomes of novel coronavirus. Available: https://www.waccbip.org/waccbip-scientists-sequencegenomes-of-novel-coronavirus/

5 Un leads call to protect most vulnerable from mental health crisis during and after COVID-19. Available: https://news.un.org/en/story/ 2020/05/1063882

6 Bonfoh B, Raso G, Koné I, et al. Research in a war zone: Bassirou Bonfoh and others offer lessons from a West African Institute that has survived ten years of conflict. Nature 2011;474:569-71. 